Acta Technologica Agriculturae 2

Nitra, Slovaca Universitas Agriculturae Nitriae, 2020, pp. 92-98

\title{
IMPROVED PROCEDURE FOR NATURAL CONVECTION GARLIC DRYING
}

\author{
Amor BOUHDJAR ${ }^{1 *}$, Hakim SEMAI ${ }^{1}$, Amal BOUKADOUM ${ }^{1}$, Sofiane ELMOKRETAR ${ }^{1}$, \\ Azzedine MAZARI ${ }^{2}$, Mohamed SEMIANI ${ }^{2}$, Aissa AMARI ${ }^{1}$ \\ ${ }^{1}$ Renewable Energy Development Centre (CDER) Route de I'Observatoire Bouzaréah Algiers, Algeria \\ ${ }^{2}$ Institut National de la Recherche Agronomique d'Alger (INRAA) Hassen Badi El Harrach Algiers, Algeria
}

\begin{abstract}
Vegetable drying is an energy consuming procedure despite the fact that it is the most efficient way to preserve agricultural products. This study investigates a new way to dry good quality garlic at lower cost. Thin garlic layer was submitted to free convection airflow at air drying temperature of $40^{\circ} \mathrm{C}, 50^{\circ} \mathrm{C}$, and $60^{\circ} \mathrm{C}$. Using the slope method, effective diffusivity coefficient was determined at each drying temperature during the first and second falling drying rate periods. Considering the former, it increased with increasing temperature. In relation to latter, it decreased with the temperature increase. However, at low drying temperatures, process keeps on going to very low moisture content; and it develops to an asymptotic value at high temperatures, indicating that shrinking at high temperature prevents evaporation of some residual moisture. Considered separately, these temperatures do not reflect the conditions met in solar drying, since in solar systems, air temperature increases during the day with increasing solar radiation. Therefore, characterization of garlic drying by means of step temperature varying - the first hour of drying at $40^{\circ} \mathrm{C}$; the second hour of drying at $50^{\circ} \mathrm{C}$, and the remaining time of drying at $60^{\circ} \mathrm{C}$ - might better correspond with conditions under solar drying and result in better understanding of the process.
\end{abstract}

Keywords: free convection airflow; stepwise increasing temperature; solar drying; effective diffusivity

Throughout the world, garlic is widely used in cuisine. It is believed that it can also be used as an effective form of plant-based medicine in many ways and thanks to these properties, it is a very important commercial product.

The annual world production is approx. 27 million tons and this makes it the tenth most harvested vegetable in the world. It is predominantly produced in few places, yet it is transported all over the world. Considered under harvest form, the vegetable mass consists of more than two third of water. This would induce higher costs in transportation, storage and other handlings. Moreover, when the rest period (60-80 days) expires, the garlic sprouts rapidly emerge after dormancy. Consequently, nutritional value in the garlic is diminished, and due to withering of the stem and trunk, garlic quality is lowered (Amiri Chayjan et al., 2012).

Drying might be the best way to lower the additional costs by reducing the weight to less than one third of the initial weight. In addition, low moisture content reduces microbial and enzymatic changes throughout the storage period, hence, extending the shelf life of the product (Sacilik and Unal, 2005; Barrozo et al., 2001).

However, drying is a process involving phase change, therefore, it is a process that consumes much more energy. It is a complicated process including transient transfer of mass and heat with certain rate processes, which may result in modifications in product quality (Al-Neama and Farkas, 2016). In order to optimize the process, knowledge on the drying mechanisms is essential. Vegetable drying is a complex phenomenon, which involves simultaneous actions of heat and mass transfer in the product. Understanding of such a phenomenon is based on a good knowledge of the balances between air and product, and control of the kinetics of the product drying and processing.

Multiple studies (Bozkir et al., 2019; Figiel, 2009; Illter et al., 2018; Younis et al., 2018; Thuwapanichayanan et al., 2014; Ruhanian and Movagharnejad, 2016; Ondro et al. 2017) considered different drying techniques, such as convective hot air, microwave drying, combined microwave convective drying, vacuum microwave drying, far infrared radiation drying assisted heat pump, combined drying. Amiri Chayjan et al. (2012) studied thin layer drying properties of garlic sheets under semi fluidized and fluidized bed conditions. The bed was submitted to convective air at different temperatures and velocities. They tested different empirical correlations in order to determine the diffusivity coefficient in the product. Sharma and Prasad (2004) undertook combined drying of garlic cloves, which consisted of continuous applying microwave of 10-40 W together with hot air at temperature of $40-70{ }^{\circ} \mathrm{C}$ and velocities of 1.0 and $2.0 \mathrm{~m} \cdot \mathrm{s}^{-1}$. They observed diffusivity dependences on initial moisture content, air temperature and microwave power at given velocities. Pezzutti and Crapiste (1997) studied changes in garlic flavour during dehydration as a function of temperature. They noticed that, at high temperatures, there is a loss of flavour strength. Afriyie et al. (2009)

Contact address: Amor Bouhdjar, Renewable Energy Development Centre (CDER) Route de l'Observatoire Bouzaréah Algiers, Algeria, e-mail: a.bouhdjar@cder.dz; bouhdjar.amor@gmail.com 
studied solar process drying in solar dryer. The efficiency of the proposed system is dependent on the local relative humidity. Furthermore, Afriyie et al. (2011) considered an improved configuration of a solar dryer and proposed several suggestions with respect to geographical regions. However, they did not investigate the characterization of the crop under evolving drying conditions. Certain properties of food, such as colour, structure, aroma compounds, and nutritional substances, are significantly influenced by high temperatures. Changes in these properties may negatively affect the product quality (Pezzutti and Crapiste, 1997).

Following an adequate drying procedure is a way to generate high quality dried garlic, in shorter drying time, with low energy consumption and better appearance. Drying kinetics are the most important information needed for dryer simulation and design.

Previous studies on drying kinetics of garlic have considered neither natural convective drying nor the effect of temperature variation during the drying process. These phenomena are often met in solar drying. This study intends to simulate drying under solar thermal drying process, which means varying temperature during the drying period and its consequences on the whole process.

\section{Material and methods}

\section{Experimental setup}

Experiments were conducted using a laboratory scale system. As shown in Fig. 1, the system consists primarily of a heat source, chimney, and perforated tray, on which the garlic slices with approx. $4.5 \mathrm{~mm}$ thickness are placed. Airflow is generated by buoyancy forces. Heat source is adjusted to the desired temperature. The air velocity is dependent on airflow temperature, chimney height and friction forces. Due to the decrease in friction forces caused by the slices during drying, the velocity tends to increase and the temperature diminishes. Subsequently, the heat source must be adjusted in order to maintain the desired temperature. Throughout the process, the velocity is increased since friction forces are diminished (they represent the only parameter that changes throughout the process). The air is heated while flowing through an electrical heater. The flowing air temperature is measured and controlled ahead of the garlic tray. The relative humidity is measured upstream of the sample tray. The air velocity is measured downstream. A digital anemometer - Prova AVM 3 - is used for these purposes; it has a resolution of $0.1 \mathrm{~m} \cdot \mathrm{s}^{-1}$ and an accuracy of $3 \%$. The temperature and relative humidity are measured using a digital combined probe $\mathrm{CHY} 722$ with an accuracy of $0.5^{\circ} \mathrm{C}$ for the temperature, and $2.5 \%$ for the relative humidity. Denver instrument balance with accuracy of $0.01 \mathrm{~g}$ was used to measure the weight of samples.

The crosswise cut, i.e. slice cut normal to the main axis, was adopted. This configuration seems to give the highest drying rate according to Babetto et al. (2011). The same initial garlic mass was used in all runs. At least three runs were performed for every case to ensure identical conditions.

During drying, garlic samples were weighed every ten minutes. Although one might consider drying state is reached when three consecutive weighing measurements

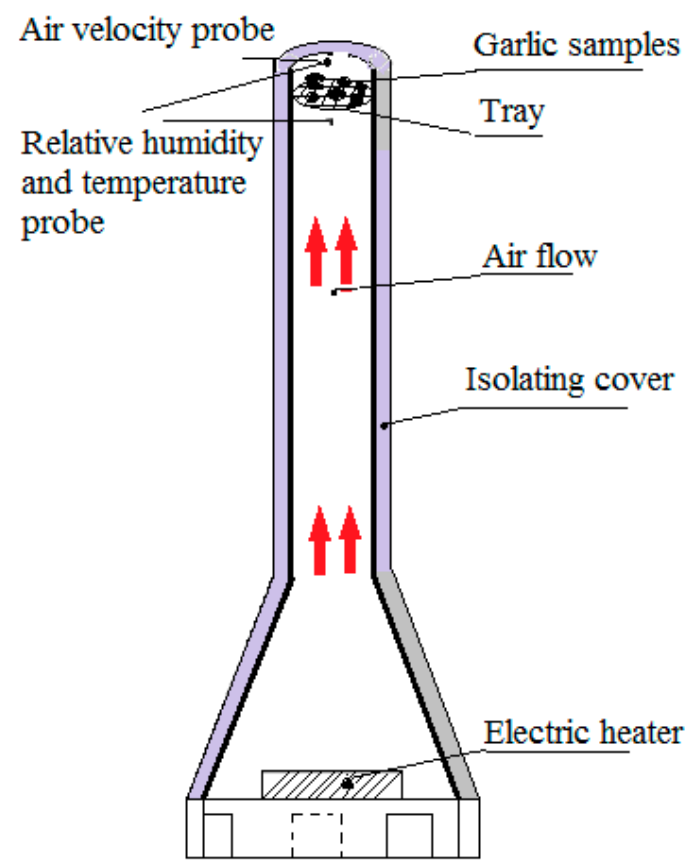

Fig. 1 Experimental setup for garlic drying

showed unchanged values, the process continued for a longer time for the purposes of analysis.

Since the paper considers the natural convection, only the temperature is adjusted. Three temperatures $-40{ }^{\circ} \mathrm{C}$; $50{ }^{\circ} \mathrm{C} ; 60^{\circ} \mathrm{C}$ - are investigated in the individual experiments. Garlic samples were placed as one layer on $110 \mathrm{~mm}$ diameter circular tray located in the chimney (Fig. 1). The tray is $170 \mathrm{~cm}$ away from the heat source in order to avoid any IR rays influence.

\section{Mathematical model and analytical solution}

Moisture movement in food material during drying is due to a combination of different mechanisms, mainly liquid diffusion, capillary flow and vapour diffusion. These mechanisms can be lumped together into a diffusion-like equation (Crapiste et al., 1988). Considering a slab of the material of thickness $2 \mathrm{l}$, through which water diffusion is predominantly taking place, and assuming that physical properties are uniform and constant over the product during the mass transfer phenomena, and assuming that the temperature is constant and uniform during phase change, a mass balance over a volume element yields the following equation:

$$
\frac{\partial M}{\partial t}=\left[\frac{\partial}{\partial x}\left(D_{\text {eff }} \frac{\partial M}{\partial x}\right)\right]
$$

where:

$M$ - moisture content, $\mathrm{kg}$ water $\cdot \mathrm{kg}$ dry matter $^{-1}$

$x$ - mass transfer path, $\mathrm{m}$

$t$ - time, $\mathrm{s}$

$D_{\text {eff }}-$ effective moisture diffusivity coefficient, $\mathrm{m}^{2} \cdot \mathrm{s}^{-1}$

It should be noted that, although we assumed constant properties, the effective diffusivity coefficient $\left(D_{\text {eff }}\right)$ varies 
considerably with product structure, moisture content and temperature. Nevertheless, it can be estimated by an analysis of the drying data (moisture $M$ vs. time $t$ ).

The appropriate initial and boundary conditions for onedimensional transport are:

$$
\begin{gathered}
\frac{\partial M}{\partial x}=0 \quad t>0 \quad x=0 \\
M=M_{e} \quad t>0 \quad x=1 \\
M=M_{i} \quad t=0 \quad 0<x<1
\end{gathered}
$$

where:

I - half the sample thickness

$M_{i}$ - initial moisture content

$M_{e}$ - moisture content at equilibrium, which might be assimilated to the moisture content when the humidity ratio is at the limit of the material and the moisture of the air flowing over the material are equivalent

When internal mass transfer is the controlling mechanism, and one-dimensional transport with constant effective diffusivity is assumed, the solution of Eq. 1 for the total moisture content in a slab might be obtained.

Using the method of separation of variables and applying the initial and boundary conditions, the solution is given by:

$$
M R=\frac{M-M_{e}}{M_{i}-M_{e}}=\frac{8}{\pi^{2}} \sum_{n=0}^{\infty} \frac{1}{(2 n+1)^{2}} \exp \left[-D_{\text {eff }} \frac{(2 n+1)^{2} \pi^{2} t}{4 l^{2}}\right]
$$

where:

$M R$ - moisture content ratio

Dimensional analysis shows that only the first term is valuable and the others might be disregarded. This leads to:

$$
M R=\frac{M-M_{e}}{M_{i}-M_{e}}=\frac{8}{\pi^{2}} \exp \left[-D_{\text {eff }} \frac{\pi^{2} t}{4 l^{2}}\right]
$$

By inserting $K=\frac{\pi^{2} D_{\text {eff }}}{4 l^{2}}$ to Eq. 4, we get:

$$
M R=\frac{8}{\pi^{2}} \exp (-K t)
$$

After taking the natural logarithm and rewriting, we get the following expression:

$$
\ln (M R)=\ln \left(\frac{8}{\pi^{2}}\right)-K t
$$

where:

$K$ - slope of the curve obtained from $\ln (M R)_{\exp }$ versus $t$

The effective diffusivity coefficient $-D_{\text {eff }}-$ can be determined as follows:

$$
D_{\text {eff }}=\frac{K}{\pi^{2}} 4 l^{2}
$$

\section{Results and discussion}

\section{Experimental results}

As it was mentioned, three temperatures were considered in this study i.e. $40{ }^{\circ} \mathrm{C}, 50{ }^{\circ} \mathrm{C}$, and $60^{\circ} \mathrm{C}$. Fig. 2 shows the temperatures recorded during each experiment run. For varying temperature, three steps were considered corresponding to $40{ }^{\circ} \mathrm{C}$ during the first hour, $50{ }^{\circ} \mathrm{C}$ during the second hour and $60{ }^{\circ} \mathrm{C}$ for the remaining time. The motivation will be explained later. On the other hand, for each temperature, air velocity increases continuously because of the increase in the flow passage section. Fig. 3 shows the velocities recorded during the experiment. The velocity corresponding to the increments in varying temperature increases more steeply due to the change in temperature.

This is because the whole system is a chimney of different sectional areas at different heights, with some bends, expansions and contractions. With smooth wall

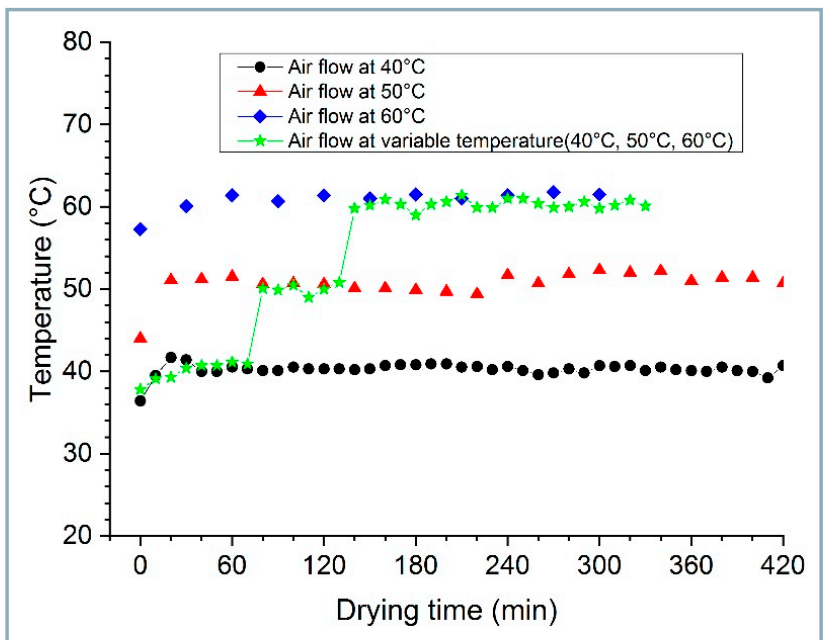

Fig. 2 Temperatures for the four tests undertaken during garlic drying

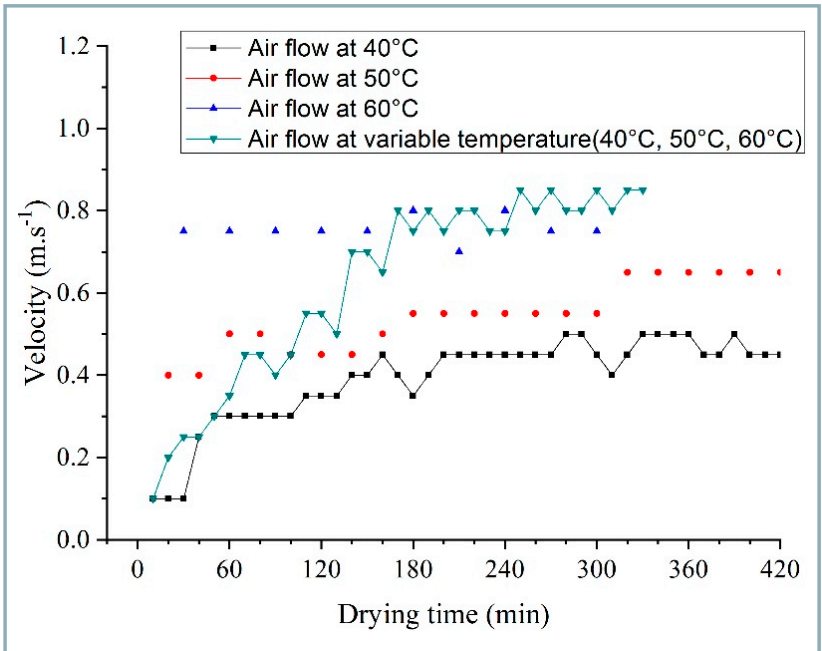

Fig. 3 Airflow velocities for different temperatures measured during the four garlic drying tests 
surfaces, friction losses between the fluid and wall surfaces are negligible in contrast to the local losses from expansion, contraction and bending (Afonso and Oliveira, 2000).

On the basis of the relation between air density and temperature (Incropera and De Witt, 1996) and fundamental principle that buoyancy pressure head must be equal to the sum of all flow pressure losses between inlet and outlet, the underlying airflow equation is given by:

$$
g \rho \beta\left(T_{H}-T_{a}\right) \Delta H=\sum K_{i} \rho \frac{v_{i}^{2}}{2}
$$

where:

$$
\begin{array}{ll}
T_{H} & - \text { airflow temperature, }{ }^{\circ} \mathrm{C} \\
T_{a} & - \text { ambient temperature, }{ }^{\circ} \mathrm{C} \\
V & - \text { airflow velocity, } \mathrm{m} \cdot \mathrm{s}^{-1} \\
g & - \text { acceleration due to gravity, } \mathrm{m} \cdot \mathrm{s}^{-2} \\
\rho & - \text { air density, } \mathrm{kg} \cdot \mathrm{m}^{-3} \\
\beta & - \text { expansion coefficient, } 1 / \mathrm{T} \\
H & - \text { chimney height, } \mathrm{m} \\
K & - \text { friction coefficient. The right side expresses all local } \\
& \text { losses }
\end{array}
$$

Considering only the passage area through the samples, tube section beyond the tray and continuity equation, Eq. 8 can be rewritten with respect to the outlet velocity as:

$$
v_{o}=\frac{\sqrt{2 g \beta\left(T_{H}-T_{a}\right) \Delta H}}{\sqrt{K_{t}+K_{p}\left(\frac{A_{t}}{A_{p}}\right)^{2}}}
$$

where:

$$
\begin{aligned}
& A \quad \text { - passage area, } \mathrm{m}^{2} \\
& v_{o} \quad \text { outlet airflow velocity, } \mathrm{m} \cdot \mathrm{s}^{-1}
\end{aligned}
$$

In this expression, the numerator expresses the driving force achieved by the chimney height and the temperature difference between the high temperature and ambient temperature enhancing the airflow. The denominator expresses the overall resistance due to friction through the passage area and the expansion beyond the tray. As the drying goes on, samples begin to shrink, increasing space between them, so the velocity gradually augments for further runs (Fig. 3). This is more evident in experiment run at varying temperature. For airflow at $40{ }^{\circ} \mathrm{C}$, the velocity started at $0.1 \mathrm{~m} \cdot \mathrm{s}^{-1}$ and finished at approx. $0.4 \mathrm{~m} \cdot \mathrm{s}^{-1}$. For airflow at $50{ }^{\circ} \mathrm{C}$, the velocity started at $0.4 \mathrm{~m} \cdot \mathrm{s}^{-1}$ and reached an average value of $0.6 \mathrm{~m} \cdot \mathrm{s}^{-1}$. Considering the airflow at $60{ }^{\circ} \mathrm{C}$, the average velocity was approx. $0.8 \mathrm{~m} \cdot \mathrm{s}^{-1}$. For the airflow at varying temperature, the velocity followed the development of the driving force, i.e. mostly the temperature difference. Product moisture decreased with increasing air temperature. With increasing temperature, the drying time was reduced due to increased thermal gradients inside the material, and as a result, drying rate increased. It should be emphasized that the entire drying process takes place during the falling drying rate period.

Measurements showed that an increase in airflow temperature from $40{ }^{\circ} \mathrm{C}$ to $60^{\circ} \mathrm{C}$ induced a decrease of the drying time of garlic slices. Consequently, the drying rate increased with an increase in the drying air temperature (Fig. 6). However, Fig. 4 shows that, after certain drying time, samples exposed to the $40^{\circ} \mathrm{C}$ airflow continue to yield some moisture, while drying rate is near zero for samples exposed to $60{ }^{\circ} \mathrm{C}$ airflow. According to several authors (Madamb et al., 1994; Ortiz-García-Carrasco et al., 2015), products exposed to high temperatures seem to shrink more and this phenomenon impacts mostly the product periphery. Consequently, the pores tend to close and decelerate water mobility and withhold some moisture as residual moisture although the airflow velocity is higher. On the other hand, with low temperature, drying process continues.

Therefore, when the samples were submitted to airflow at an increasing temperature - at $40{ }^{\circ} \mathrm{C}$ for the first hour, $50{ }^{\circ} \mathrm{C}$ at the second hour, and $60^{\circ} \mathrm{C}$ for the remaining time it was observed that the drying time is shorter compared to the previous cases when the temperature was constant during the whole run (Fig. 5). Moreover, the drying rate decreased steadily throughout the whole process for the constant temperatures.

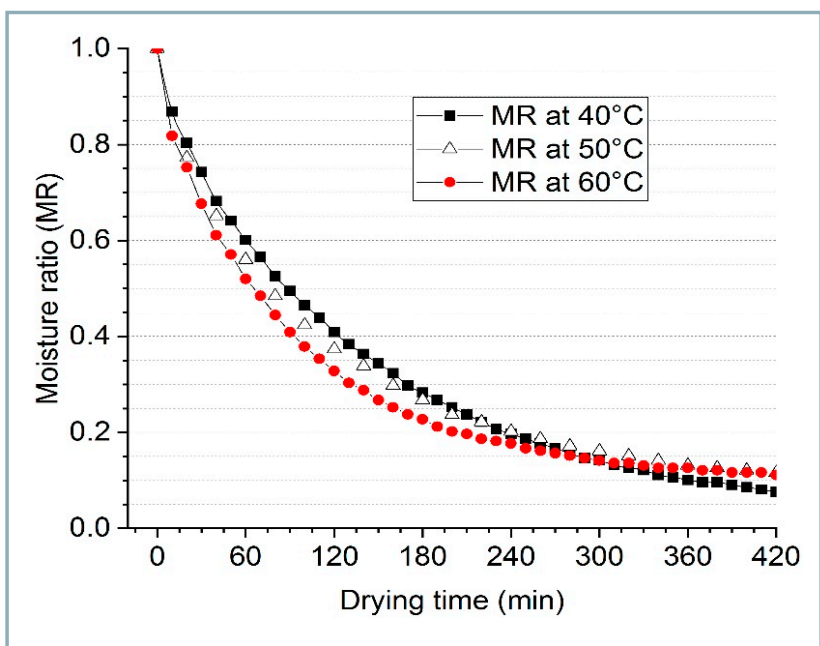

Fig. 4 Moisture content during drying at uniform temperatures

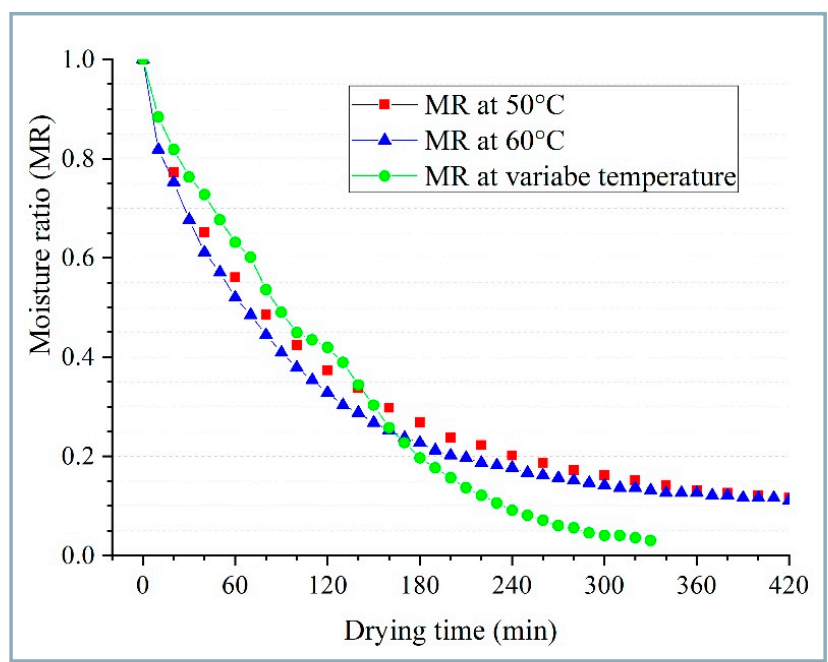

Fig. 5 Moisture content ratio during drying at varying temperature 


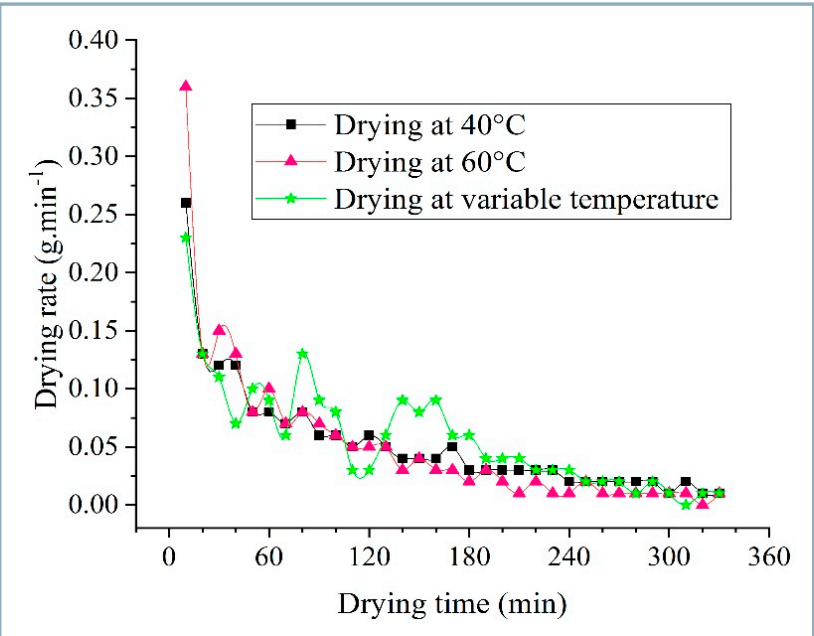

Fig. 6 Drying rate vs. time for drying under airflow at uniform and varying temperatures

Moisture content ratio obtained for samples submitted to a $60{ }^{\circ} \mathrm{C}$ airflow in $270 \mathrm{~min}$ was identical to moisture content obtained in 190 min at varying temperature airflow.

The analytical solution deduced previously considered several assumptions, which cannot be met in agricultural product drying.

Therefore, Ruhanian and Movagharnejad (2016) suggest semi-empirical solutions, five of which are used mostly in forced convection drying or other form of drying, but, to the authors' knowledge, have not been used in natural convection drying (Table 1).

Table 1 Mathematical expressions used to describe thinlayer drying kinetics

\begin{tabular}{|l||c|}
\hline Model name & Mathematical formulation \\
\hline Newton & $M R=\exp (-k t)$ \\
\hline Henderson and Pabis & $M R=a \exp (-k t)$ \\
\hline Logarithmic & $M R=a \exp (-k t)+c$ \\
\hline Two term model & $M R=a \exp \left(-k_{1} t\right)+b \exp \left(-k_{2} t\right)$ \\
\hline Page & $M R=\exp \left(-k t^{n}\right)$ \\
\hline
\end{tabular}

Fig. 6 shows the deduced drying rates. It was observed that the process went steadily in decrease for uniform temperatures. On the other hand, for varying temperature, the drying rate seemed to jump at every increase in

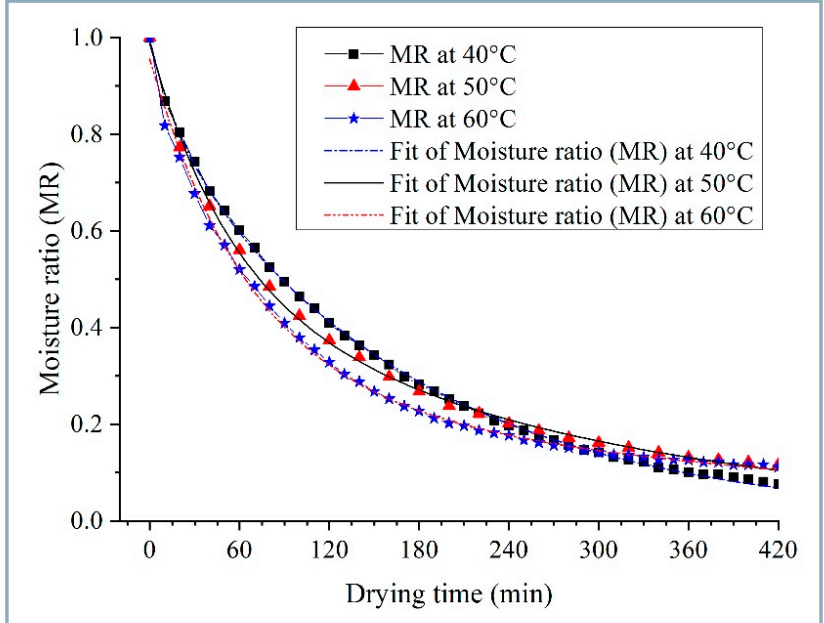

Fig. 7 Moisture content ratio during drying at uniform temperature and fitted model

temperature. This explains why there is a rapid decrease in moisture content (Fig. 5).

According to Madamb et al. (1994) and Ortiz-GarcíaCarrasco et al. (2015), shrinking of agricultural products occurs when they are submitted to high temperatures drying process. High temperature tends to squeeze samples during shrinking. The pressure is mostly exercised on the outside of the product and closes the pores, not allowing the fluid to evaporate. This results in the reduced water effective diffusivity, implying that some residual moisture might have been preserved in the product dried at high temperature. On the contrary, product dried at low temperature keeps on drying as long as the outside air absorbs the extracted water (Fig. 4).

The experimental drying data were used to find out the most suitable model among the five different models proposed by Ruhanian and Movagharnejad (2016).

The most suitable fitness of the empirical model to the experimental data is gauged through the coefficient of determination $\left(R^{2}\right)$ and the reduced chi-square $\left(\chi^{2}\right)$, which should be the highest coefficient of determination $\left(R^{2}\right)$ and the lowest reduced chi-square $\left(\chi^{2}\right)$ (Table 2$)$.

Accordingly, the two-term model, for which different constant values are generated, presents the highest coefficient of determination and the lowest reduced chisquare (Table 3, Fig. 7).

Table 2 Statistical results obtained for thin layer drying models for garlic slices under natural convection at different temperatures

\begin{tabular}{|c|c|c|c|c|c|c|}
\hline \multirow[t]{2}{*}{ Model } & \multicolumn{2}{|c|}{$T=40^{\circ} \mathrm{C}$} & \multicolumn{2}{|c|}{$T=50^{\circ} \mathrm{C}$} & \multicolumn{2}{|c|}{$T=60^{\circ} \mathrm{C}$} \\
\hline & $\chi^{2}$ & $R^{2}$ & $\chi^{2}$ & $R^{2}$ & $\chi^{2}$ & $R^{2}$ \\
\hline Newton & $9.62 \mathrm{E}-04$ & 0.98351 & 0.00313 & 0.94463 & 0.00395 & 0.91622 \\
\hline Henderson and Pabis & 3.19E-04 & 0.99453 & 0.00189 & 0.96657 & 0.00208 & 0.95591 \\
\hline Logarithmic & $1.55 \mathrm{E}-04$ & 0.99734 & $2.83 \mathrm{E}-04$ & 0.99499 & $1.82 \mathrm{E}-04$ & 0.99615 \\
\hline Two-term & 2.63E-05 & 0.99958 & 8.57E-05 & 0.99849 & $1.24 \mathrm{E}-04$ & 0.99738 \\
\hline Page & 3.65E-05 & 0.99924 & $9.08 \mathrm{E}-05$ & 0.99745 & 2.64E-04 & 0.99261 \\
\hline
\end{tabular}


Table 3 Constants and coefficients for the best-fitted model (two-term model)

\begin{tabular}{|l||c|c|c|c|c|c|}
\hline Temperature & $\boldsymbol{a}$ & $\boldsymbol{k}_{\mathbf{1}}$ & $\boldsymbol{b}$ & $\boldsymbol{k}_{\mathbf{2}}$ & $\boldsymbol{\chi}^{\mathbf{2}}$ \\
\hline \hline $\boldsymbol{T}=\mathbf{4 0}$ & 0.84535 & 0.00599157 & 0.14864 & 0.05346113 & $2.63 \mathrm{E}-05$ \\
\hline $\boldsymbol{T}=\mathbf{5 0}$ & 0.7988 & 0.01092964 & 0.16866 & 0.00084564 & $8.57 \mathrm{E}-05$ & 0.99955 \\
\hline $\boldsymbol{T}=\mathbf{6 0}$ & 0.81 & 0.01228058 & 0.136412 & 0.00054955 & $1.24 \mathrm{E}-04$ \\
\hline
\end{tabular}

\section{Effective diffusivity coefficient determination}

Adopting the slope method (Madamb et al., 1996; Caccavale et al., 2016), the curve of $\ln (M R)$ versus drying time generates the effective diffusivity coefficient through the fitted linear relation to these curves.

$$
\ln (M R)=\ln \left(\frac{8}{\pi^{2}}\right)-\frac{D_{\text {eff }} \pi^{2}}{4 l^{2}} t
$$

So from the plot of $\ln (M R)$, we get:

$$
D_{\text {eff }}=\frac{\text { Slope } \cdot 4 I^{2}}{\pi^{2}}
$$

A close look at Figs. 4 and 6 shows that nearly $75 \%$ of the moisture is extracted during the first falling drying rate period and the remaining moisture is extracted during the second falling drying rate period. In order to generate the fitting function, we will consider the process taking place following the two periods. For each, we deduced an effective diffusivity coefficient.

By adopting the aforementioned method, the effective diffusivity coefficients for each temperature were obtained as given in Table 4.

The effective diffusivity coefficient increased with the increase in temperature and consequent slight increase in airflow velocity even though it never reached $1 \mathrm{~m} \cdot \mathrm{s}^{-1}$. On the other hand, in the second falling drying rate period, the effective diffusivity coefficient decreased with increasing temperature (Table 5).

Fig. 4 indicates that, at $40{ }^{\circ} \mathrm{C}$, the drying process continued beyond the point where it has almost stopped for $60^{\circ} \mathrm{C}$.

Therefore, the decrease in effective diffusivity might be the consequence of pore restriction at the periphery of samples during the second falling drying rate period.

To minimize the effect of shrinking, samples were dried under hot air at increasing temperature. During the first period of one hour, the temperature was fixed at $40{ }^{\circ} \mathrm{C}$, during the second period of one hour, the temperature was fixed at $50{ }^{\circ} \mathrm{C}$, and during the remaining time of drying, the temperature was fixed at $60^{\circ} \mathrm{C}$ (Fig. 5). During this process, the effective diffusivity kept on increasing with every increase in temperature (Table 6).

The effective diffusivity coefficient value obtained during each period nearly corresponds to the one obtained during the first falling drying rate period of the corresponding uniform temperature.

Therefore, the shrinking, which occurred when the temperature was ramped up, did not have the same impact when the temperature was increased during the same process. Moreover, the drying time was reduced. The moisture content ratio obtained in 200 min under varying temperature was reached in 250 min when drying at $60^{\circ} \mathrm{C}$ and in 300 min when drying at $50^{\circ} \mathrm{C}$ (Fig. 4).

Table 4 Effective diffusivity coefficients at different temperatures during the first falling drying rate period

\begin{tabular}{|l||c|c|}
\hline Temperature & Effective diffusivity coefficient $\mathbf{~ ( m}^{\left.\mathbf{2} \cdot \mathbf{s}^{-\mathbf{1}}\right)}$ & $\boldsymbol{R}^{\mathbf{2}}$ \\
\hline $\mathbf{4 0}{ }^{\circ} \mathbf{C}$ & $8.98211 \mathrm{E}-10$ & 0.99774 \\
\hline $\mathbf{5 0}{ }^{\circ} \mathbf{C}$ & $9.46134 \mathrm{E}-10$ & 0.99328 \\
\hline $\mathbf{6 0}^{\circ} \mathbf{C}$ & $10.0912 \mathrm{E}-10$ & 0.99742 \\
\hline
\end{tabular}

Table 5 Effective diffusivity coefficients at different temperatures during the second falling drying rate period

\begin{tabular}{|l||c|c|}
\hline Temperature & Effective diffusivity coefficient $\left.\mathbf{( m}^{\mathbf{2}} \cdot \mathbf{s}^{-\mathbf{1}}\right)$ & $\boldsymbol{R}^{\mathbf{2}}$ \\
\hline \hline $\mathbf{4 0}{ }^{\circ} \mathbf{C}$ & $4.7627 \mathrm{E}-10$ & 0.99892 \\
\hline $\mathbf{5 0}{ }^{\circ} \mathbf{C}$ & $3.08954 \mathrm{E}-10$ & 0.9913 \\
\hline $\mathbf{6 0}{ }^{\circ} \mathbf{C}$ & $2.99015 \mathrm{E}-10$ & 0.99614 \\
\hline
\end{tabular}

Table 6 Effective diffusivity coefficients during drying process at varying temperatures

\begin{tabular}{|l||c|c|}
\hline Period & Effective diffusivity & $\boldsymbol{R}^{\mathbf{2}}$ \\
\hline First period $\left(\boldsymbol{T}=\mathbf{4 0}^{\circ} \mathbf{C}\right)$ & $8.9958 \mathrm{E}-10$ & 0.99602 \\
\hline Second period $\left(\boldsymbol{T}=\mathbf{5 0}^{\circ} \mathbf{C}\right)$ & $8.78125 \mathrm{E}-10$ & 0.96105 \\
\hline Remaining time $\left(\boldsymbol{T}=\mathbf{6 0}^{\circ} \mathbf{C}\right)$ & $10.7678 \mathrm{E}-10$ & 0.99904 \\
\hline
\end{tabular}




\section{Conclusions}

This study was undertaken to investigate the behaviour of thin layer garlic drying under free convection airflow. Investigating three temperatures with lower negative impact on final product quality, it came out that air velocity was relatively low. Application of increasing stepwise airflow temperature made samples dry in shorter time. This procedure implemented the first falling drying rate period behaviour for every step temperature. This finding was confirmed by the determination of the effective diffusivity coefficient generated for both uniform and stepwise increased temperatures during the first falling drying rate period. This new procedure lets the garlic dry in shorter time, resulting in lower energy consumption and making it more economically viable. This procedure can be used in modelling of solar energy systems and can contribute to shorter drying time and to get good product quality, since the operating temperatures are lower than $60^{\circ} \mathrm{C}$.

\section{Acknowlegments}

This work was supported by the Directorate General for Scientific Research and Technological Development, Algiers Algeria.

\section{References}

AFONSO, C. - OLIVEIRA, A. 2000. Solar chimneys: simulation and experiment. In Energy and Buildings, vol. 32, pp. 71-79.

AFRIYIE, J. K. - NAZHA, M. A. A. - RAJAKARUNA, H. - FORSON, F. K. 2009. Experimental investigations of a chimney dependent solar crop dryer. In Renewable Energy, vol. 34, pp. 217-222.

AFRIYIE, J. K. - RAJAKARUNA, H. - NAZHA, M. A. A. - FORSON, F. K 2011. Simulation and optimisation of the ventilation in a chimneydependent solar crop dryer. In Solar Energy, vol. 85, pp. 1560-1573. AL-NEAMA, M. A. - FARKAS, I. 2016. Energy analysis of active solar drying system connected with photovoltaic modules. In Energy and Environment, pp. 187-196.

AMIRI CHAYJAN, R. - SALARI, K. - SHADIDI, B. 2012. Modeling some drying characteristics of garlic sheets under semi fluidized and fluidized bed conditions. In Research in Agricultural Engineering, vol. 58, pp. 73-82.

BABETTO, A. C. - FREIRE, F. B. - BARRAZO, M. A. S. - FREIRE, J. T. 2011. Drying of garlic slices: Kinetics and nonlinearity measures for selecting the best equilibrium moisture content equation. In Journal of Food Engineering, vol. 107, pp. 347-352.

BARROZO, M. A. S. - SOUZA, A. M. - COSTA, S. M. - MURATA, V. V. 2001. Simultaneous heat and mass transfer between air and soybean seeds in a concurrent moving bed. In International Journal of Food Science and Technology, vol. 36, pp. 393-399.

BOZKIR, H. - RAYAMN ERGÜN, A. - TEKGÜL, Y. - BAYSAL, T. 2019. Ultrasound as pretreatment for drying garlic slices in microwave and convective dryer. In Food Science and Biotechnology, vol. 28, pp. 347-354.
CACCAVALE, P. - De BONIS, M. V. - RUOCCO, G. 2016. Conjugate heat and mass transfer in drying: a modeling review. In Journal of Food Engineering, vol. 176, pp. 28-35.

CRAPISTE, G. H. - WHITAKER, S. - ROTSTEIN, E. 1988. Drying of cellular material - I. A mass transfer theory. In Chemical Engineering Science, vol. 43, pp. 2919-2928.

FIGIEL, A. 2009. Drying kinetics and quality of vacuum microwave dehydrated garlic cloves and slices. In Journal of Food Engineering, vol. 94, pp. 98-104

ILTER, I. - AKYIL, S. - DEVSEREN, E. - OKUT, D. - KOÇ, M. - KAYMAK ERTEKIN, F. 2018. Microwave and hot air drying of garlic puree: drying kinetics and quality characteristics. In Heat and Mass Transfer, vol. 54 pp. 2101-2212.

INCROPERA, F. P. - De WITT, D. P. 1996. Introduction to heat transfer $3^{\text {rd }}$ ed. New York/Chichester/Brisbane/Toronto/Singapore : John Wiley and Sons.

MADAMB, P. S. - DRISCOLL, R. H. - BUCKLE, K. A. 1994. Shrinkage, density and porosity of garlic during drying. In Journal of Food Engineering, vol. 23, pp. 309-319.

MADAMB, P. S. - DRISCOLL, R. H. - BUCKLE, K. A. 1996. The thin layer drying characteristics of garlic slices. Journal of Food Engineering, vol. 29, pp. 75-97.

ONDRO, T. - HÚLAN, T. - VITÁZEK, I. 2017. Non-isothermal kinetic analysis of the dehydroxylation of kaolinite in dynamic air atmosphere. In Acta Technologica Agriculturae, vol. 20, no. 2, pp. 52-55.

ORTIZ-GARCÍA-CARRASCO, B. - YAÑEZ-MOTA, E. - PACHECOAGUIRRE, F. M. - RUIZ-ESPINOSA, H. - GARCÍA-ALVARADO, M. A. CORTÉS-ZAVALETA, O. - RUIZ-LOPÉZ, I. I. 2015. Drying of shrinkable food products: Appraisal of deformation behavior and moisture diffusivity estimation under isotropic shrinkage. In Journal of Food Engineering, vol. 144, pp. 138-147.

PEZZUTTI, A. - CRAPISTE, G. H. 1997. Sorptional equilibrium and drying characteristics of garlic. In Journal of Food Engineering, vol. 31, pp. 113-123.

RUHANIAN, S. - MOVAGHARNEJAD, K. 2016. Mathematical modeling and experimental analysis of potato thin-layer drying in an infrared-convective dryer. In Engineering in Agriculture, Environment and Food, vol. 9, pp. 84-91.

SACILIK, K. - UNAL, G. 2005. Dehydration characteristics of Kastamonu garlic slices. In Biosystems Engineering, vol. 92, pp. 207-215.

SHARMA, G. P. - PRASAD, S. 2004. Effective moisture diffusivity of garlic cloves undergoing microwave convective drying. In Journal of Food Engineering, vol. 65, pp. 609-617.

THUWAPANICHAYANAN, R. - PRACHAYAWARAKORN, S. SOPONRONNARIT, S. 2014. Heat and moisture transport behavior and quality of chopped garlic undergoing different drying methods. In Journal of Food Engineering, vol. 136, pp. 34-41.

YOUNIS, M. C. - ABDELKARIM, D. - ZEIN EL-ABDEIN, A. 2018. Kinetics and mathematical modeling of infrared thin-layer drying of garlic slices. In Saudi Journal of Biological Sciences, vol. 25, pp. 332-338. 